
Kovács

\title{
Crystallization of $\mathrm{Cu}_{60} \mathrm{Zr}_{20} \mathrm{Ti}_{20}$ bulk metallic glass by high pressure torsion
}

https://doi.org/10.1515/rams-2019-0037

Received Jul 19, 2019; accepted Nov 18, 2019

Abstract: Bulk metallic glass of $\mathrm{Cu}_{60} \mathrm{Zr}_{20} \mathrm{Ti}_{20}$ composition has been synthesized by copper mold casting. Slices of the as-cast glass has been subjected to severe plastic deformation by high-pressure torsion for different whole turns. The microstructure and the thermal behavior of the deformed disks have been investigated by X-ray diffraction and differential scanning calorimetry. It was confirmed that the initial compression preceding the high pressure torsion induces crystallized structure, which shows only minor further changes upon the severe plastic shear deformation achieved by twisting the sample. The X-ray line profiles have been evaluated by the Convolutional Whole Profile Fitting algorithm in order to determine the evolution of the microstructural parameters, such as the median and variance of the crystallite size distribution, average crystallite size and dislocation density as a function of the number of revolutions. Hardness measurements by nanoindentation have also been carried out on the as-cast alloys and the deformed disks.

Keywords: amorphous alloys; sever plastic deformation; hardness; glass transition

\section{Introduction}

Bulk metallic glasses (BMGs) exhibiting only short range atomic order have received increasing attention in the last

\footnotetext{
^Corresponding Author: Âdám Révész: Department of Materials Physics, Eötvös University, Budapest, H-1518, P.O.B. 32, Budapest, Hungary; Email: reveszadam@ludens.elte.hu; Fax:+36-1-372-2811 András Horváth, Gábor Ribárik, Zsolt Kovács: Department of Materials Physics, Eötvös University, Budapest, H-1518, P.O.B. 32, Budapest, Hungary

Erhard Schafler: Physics of Nanostructured Materials, Faculty of Physics, University of Vienna, A-1090 Vienna, Austria

David J. Browne: School of Mechanical and Materials Engineering, University College Dublin, Belfield, Dublin 4, Ireland
}

O̊ Open Access. (C) 2019 Á. Révész et al., published by De Gruyter. (Cc) BY 4.0 License couple of decades due to their special mechanical properties, such as high tensile strength and hardness, large elastic strain and high stored elastic energy [1-3], which are directly connected to the lack of structural faults such as dislocations and grain boundaries [4-7]. Nevertheless, the wide-spread application of BMGs has not occurred yet because of brittleness, expensive alloying components and the required precise preparation conditions [4-8].

Among the large variety of BMG classes, Cu-based metallic glasses are one of the most intensively studied alloys, since they possess high glass forming ability (GFA) [9, 10], excellent corrosion resistance $[11,12]$ and some intrinsic plasticity [13-15]. It was found that the thermal stability is decreasing with increasing Ti-content and the maximum belongs to $\mathrm{Cu}_{64} \mathrm{Zr}_{28.5} \mathrm{Ti}_{17.5}$ [16]. The glassy concentration range in the ternary $\mathrm{Cu}$-Zr-Ti system can be predicted by the calculation of vacancy formation energy, mixing enthalpy and configurational entropy [17]. The GFA of the binary $\mathrm{Cu}-\mathrm{Zr}$ system is so high in wide composition range that it is possible to cast alloys in bulk glassy form $[18,19]$. During tensile deformation Cu-Zr-based BMGs polymorphically precipitate nanocrystals [20], which are responsible for macroscopically detectable plastic strain and work hardening [21]. Following the glass transition, devitrification of the ternary $\mathrm{Cu}-\mathrm{Zr}$-Ti system usually occurs in two subsequent crystallization events, i.e. the first stage is characterized by the formation of $\mathrm{Cu}_{51} \mathrm{Zr}_{14}$ nanocrystals embedded in the residual amorphous matrix [22], while the crystallization is completed during the second step, when the precipitation of hexagonal $\mathrm{Cu}_{2} Z \mathrm{ZrTi}$-like phase takes place [23]. Ordered local nanocrystallization can also take place in a Cu-Zr-Ti metallic glass during ion bombarding, which feasibility strongly correlates with the glass transition [24]. Surprisingly, the devitrification of a $\mathrm{Cu}_{60} \mathrm{Zr}_{30} \mathrm{Ti}_{10}$ metallic glass commences by the nucleation of $\mathrm{Cu}$-rich cubic nanometer-sized crystals which are randomly distributed in the residual amorphous matrix [25]. Isothermal annealing of the $\mathrm{Cu}_{60} \mathrm{Zr}_{20} \mathrm{Ti}_{20}$ alloy below the glass transition revealed that atomic diffusion in the amorphous matrix proceeds with a decreasing nucleation rate [26]. 
Besides nanocrystallization, the ductility of metallic glasses can be significantly increased by dispersing the macroscopic external strain among several competitive shear bands developed in the amorphous structure either by structural and/or compositional inhomogeneities [27, 28] or by surface constraint techniques [29-36]. Among the large number of severe plastic deformation techniques, high-pressure torsion (HPT) has received a remarkable attention in the last decades due to the very high applied shear strain in a practically large sample volume [37, 38]. In brief, during the HPT deformation technique, a specimen of disk-shape is placed between two stainless steel anvils and subjected to simultaneous uniaxial load and torsional straining $[39,40]$. The microstructural and morphological features, mechanical properties and thermal behavior of an amorphous Cu-Zr-Ti metallic ribbon pieces compacted and deformed by HPT have been correlated by the calculated temperature evolution in the HPT-disk based on a heat-conduction model [41-43]. The effect of the parameters of the HPT-device, i.e. the shear rate [44] and accumulated shear were demonstrated in details [45].

In the present research the effect of shear strain on the microstructure, thermal stability and mechanical behavior of amorphous $\mathrm{Cu}_{20} \mathrm{Zr}_{20} \mathrm{Ti}_{20} \mathrm{BMG}$ deformed by HPT will be presented.

\section{Experimental}

\subsection{Sample preparation}

Bulk metallic glass rod (diameter $5 \mathrm{~mm}$ ) with $\mathrm{Cu}_{60} \mathrm{Zr}_{20} \mathrm{Ti}_{20}$ nominal composition was cast by suction casting into a $\mathrm{Cu}$-mold in an arc furnace from liquid state under purified Ar atmosphere. The master alloy was produced in the same furnace by arc melting the high-purity components (>99.9\%) and then the ingot was flipped and remelted several times, to ensure compositional homogeneity.

For subsequent HPT processing, the as-cast BMG cylinder were cut into slices with a height of $1 \mathrm{~mm}$ and radius $2 \mathrm{~mm}$. The HPT procedure was carried out on these disks in air, under an applied pressure of $8 \mathrm{GPa}$ at room temperature with an angular velocity of $\omega=0.2$ revolution $/ \mathrm{min}$ for $N=0.2, N=1$ and $N=5$ revolution. For comparison a disk without torsion $(\mathrm{N}=0)$ was also prepared. Generally, the shear strain for torsion deformation at a radius $r$ can be represented by

$$
\gamma=\frac{\theta r}{L}=\frac{2 \pi N r}{L}
$$

where $\theta$ and $\mathrm{L}$ are the rotation angle and the thickness of the disk, respectively. For large strains (i.e. at the perimeter of the disks), the corresponding accumulated strain can be given as [38]

$$
\epsilon \approx \ln \left(\frac{\theta r}{L}\right)=\ln \left(\frac{2 \pi N r}{L}\right)
$$

Table 1 tabulates the $\gamma$ and $\epsilon$ values for all the deformed disks at the perimeter $(\mathrm{r}=2 \mathrm{~mm})$. In the experimental setup of the HPT the stainless steel anvils followed a constrained geometry [37]. Marker lines drawn on the surface of the disks indicate that slippage between the disk and anvil was negligible.

Table 1: Calculated shear strain and accumulated strain values for the different HPT deformed disks obtained at the perimeter $(r=2 \mathrm{~mm})$ with a final thickness $L=0.9 \mathrm{~mm}$.

\begin{tabular}{ccc}
\hline $\begin{array}{c}\text { Number of turns } \\
(\mathrm{N})\end{array}$ & Shear strain $(\gamma)$ & $\begin{array}{c}\text { Accumulated } \\
\text { strain }(\boldsymbol{\epsilon})\end{array}$ \\
\hline 0.2 & 2,8 & 1,03 \\
1 & 14,0 & 2,64 \\
5 & 69,8 & 4,24 \\
\hline
\end{tabular}

\subsection{Microstructural characterization}

The microstructure of the as-cast and deformed samples was examined by X-ray diffraction. The measurements were carried out on a Rigaku SmartLab diffractometer in $\theta-2 \theta$ geometry using $\mathrm{Cu}-\mathrm{K} \alpha$ radiation. The data were collected from $20^{\circ}$ to $75^{\circ}$ with a step size of $0.01^{\circ}$. Cell parameters of the crystalline phases were determined from peak positions after deconvolution of the overlapping peaks.

$\mathrm{X}$-ray diffraction peak profile analysis is a powerful tool to determine the microstructural properties of nanostructured materials. In the present investigations we applied the Convolutional Multiple Whole Profile (CMWP) fitting procedure which incorporates the direct fit of the whole measured diffraction pattern by the sum of background, theoretically constructed profile functions and measured instrumental profiles [46]. As known, the contribution of the coherently scattering domain size and the lattice strain on peak broadening can be separated on the basis of their different diffraction order dependence. In brief, these profile functions are determined for each reflection of each crystalline phase as the inverse Fourier transform of the product of the theoretically well-established size and strain Fourier coefficients providing both the size and strain parameters of the microstructure [47]. It is assumed 
that the crystallites have a lognormal size distribution:

$$
G(x)=(2 \pi)^{-1 / 2} \sigma^{-1} x^{-1} \exp \left[-(\ln (x / m))^{2} / 2 \sigma^{2}\right],
$$

where $\sigma$ and $\mathrm{m}$ are the variance and median of the distribution, respectively. Accordingly the average size of the coherently scattering domains can be expressed as

$$
\langle\mathrm{D}\rangle=m \exp \left(2.5 \sigma^{2}\right) .
$$

The CMWP algorithm also provides the strain parameters, i.e. the average dislocation density $(\rho)$ can also be determined.

Imaging of the sample surface of the as-cast and deformed samples was performed in a tabletop Hitachi TM4000Plus scanning electron microscope (SEM) in back scattered electron (BSE) mode using $10 \mathrm{keV}$ electrons.

\subsection{Thermal characterization}

A Perkin Elmer power compensated differential scanning calorimeter (DSC) was applied to investigate the thermal behavior and crystallization sequence of the as-cast $\mathrm{Cu}_{60} \mathrm{Zr}_{20} \mathrm{Ti}_{20}$ BMG rod and the deformed specimens in a linear heating ramp performed at a scan rate of $20 \mathrm{~K} / \mathrm{min}$. All measurements were carried out under protective Ar atmosphere. The temperature and the enthalpy were calibrated by using pure In and Al. Each measurement was followed by a second run in order to obtain the baseline.

\subsection{Hardness measurements}

Depth sensing nanoindentation tests were carried out on polished circular planes of the deformed HPT disks and on a reference as-cast sample. For each samples, 225 nanoindentations tests arranged in $15 \times 15$ matrix with neighbor spacing of $50 \mu \mathrm{m}$ were carried out by an UMIS CSIRO nanoindentor using a Vickers indenter head and applying maximum loads of $50 \mathrm{mN}$ at a loading rate of $0.5 \mathrm{mN} / \mathrm{s}$. The hardness in each test was determined by the Oliver-Pharr method [48]. Based on the high number of hardness values, a hardness distribution was calculated for each sample using a $0.25 \mathrm{GPa}$ bin size.

\section{Results and discussion}

The XRD pattern of the as-cast $\mathrm{Cu}_{60} \mathrm{Zr}_{20} \mathrm{Ti}_{20}$ BMG is dominated by a broad halo ( $2 \theta \sim 42 \mathrm{deg}$ ) which confirms that the

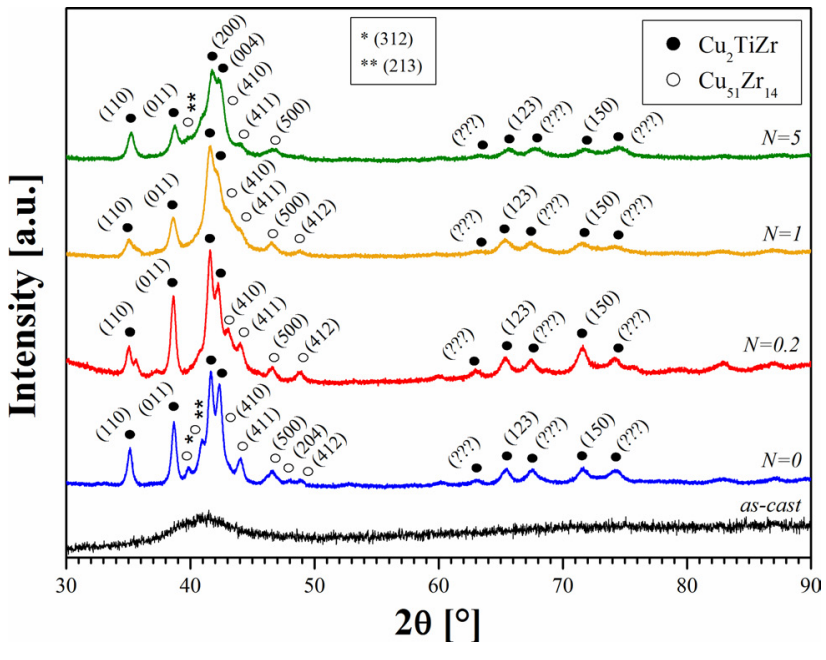

Figure 1: XRD patterns of as-cast, compressed $(\mathrm{N}=0)$ and different $(\mathrm{N}=0.2,1,5) \mathrm{HPT}$ deformed $\mathrm{Cu}_{60} \mathrm{Zr}_{20} \mathrm{Ti}_{20}$ samples. Diffraction peaks of the crystalline $\mathrm{Cu}_{2} \mathrm{ZrTi}$ and $\mathrm{Cu}_{51} \mathrm{Zr}_{14}$ phases are indicated.

material is X-ray amorphous (Figure 1). The corresponding continuous heating DSC thermogram exhibits the typical features of a metallic glass, i.e. the glass transition $\left(\mathrm{T}_{g}=703 \mathrm{~K}\right)$ is followed by a two-step crystallization process characterized by $\mathrm{T}_{1}=742 \mathrm{~K}$ and $\mathrm{T}_{2}=782 \mathrm{~K}$ transformation temperatures (see Figure 2a), in agreement with literature data [23]. The exothermic heat release $\left(\Delta \mathrm{H}_{B M G}=56\right.$ $\mathrm{J} / \mathrm{g}$ ) corresponds to the enthalpy of crystallization is somewhat larger than that was obtained for an amorphous ribbon of similar composition $\left(\Delta \mathrm{H}_{\text {ribbon }}=49 \mathrm{~J} / \mathrm{g}\right)$ processed by the melt-spinning technique [23]. Isothermal annealing experiment taken close to the glass transition ( $\left.\mathrm{T}_{a n n}=700 \mathrm{~K}\right)$ exhibits a monotonously decreasing curve (Figure $2 \mathrm{~b}$ ). The lack of any significant exothermic peak on the isothermal heat signal may correspond to limited nucleation of crystalline products, while the decaying signal relates to a simple growth process of very tiny crystalline embryos, which are already present in the as-cast glass [49].

The diffractograms taken on the surface of the deformed disks indicate that the plastic deformation results in a drastic change in the microstructure (see Figure 1). All patterns exhibit several well defined Bragg-peaks corresponding to intensive crystallization, nevertheless a minor amorphous component can still be recognized for each deformation state. The XRD pattern corresponding to the $\mathrm{N}=0$ disk is already characterized by the peaks of hexagonal $\mathrm{Cu}_{51} \mathrm{Zr}_{14}$ (p6/m) and hexagonal $\mathrm{Cu}_{2} \mathrm{ZrTi}\left(\mathrm{p} 6_{3} / \mathrm{mmc}\right)$ phases. It is noted that these phases are identical to those that form after thermal annealing of the same system [23]. Interestingly, the HPT deformation of the Cu-Zr-Ti system produced by melt-spinning (obtained at a significantly higher cooling rate) results in a remarkably different mi- 

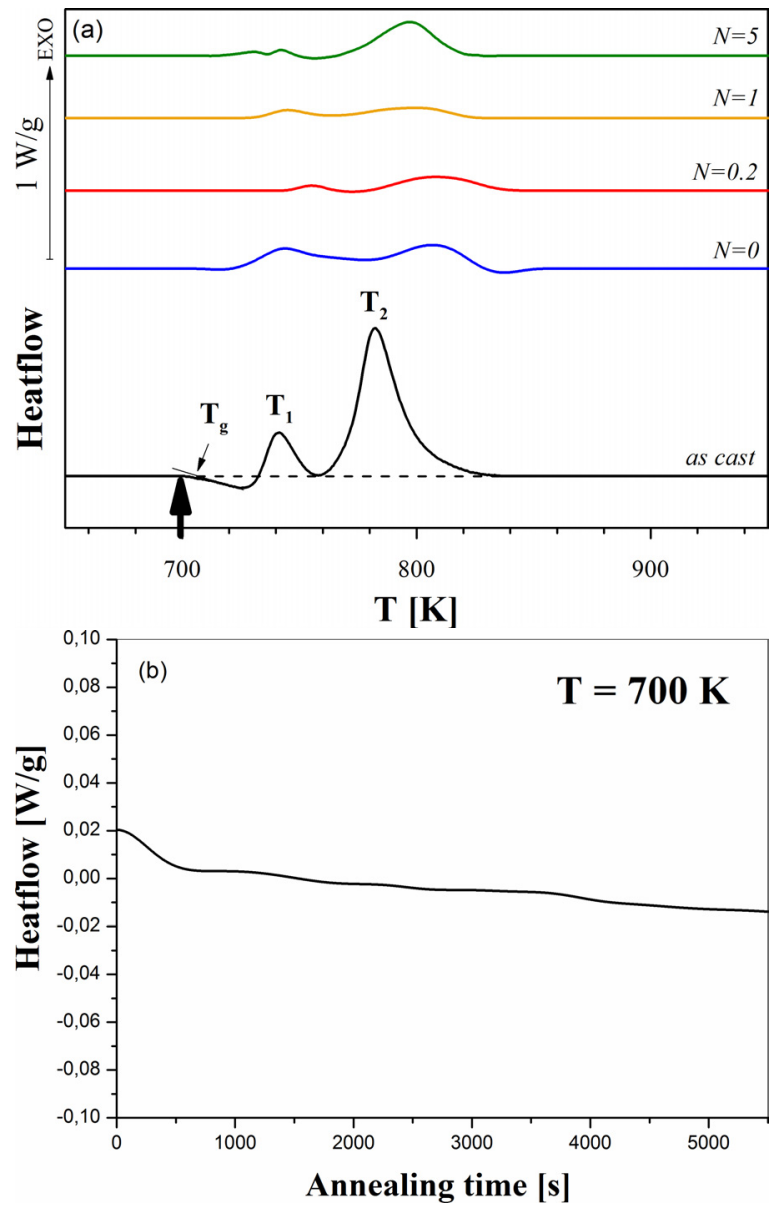

Figure 2: (a) DSC curves of as-cast, compressed $(\mathrm{N}=0)$ and different $(\mathrm{N}=0.2,1,5)$ HPT deformed $\mathrm{Cu}_{60} \mathrm{Zr}_{20} \mathrm{Ti}_{20}$ samples. The $\mathrm{T}_{g}$ glass transition and the $T_{1}$ and $T_{2}$ crystallization peak temperatures are indicated on the as-cast curve. (b) Isothermal annealing obtained on the as-cast BMG at $\mathrm{T}_{a n n}=700 \mathrm{~K}$.

crostructure [41]. Namely, the deformed melt-spun material still contained a major amorphous component, with only 20 percent of $\mathrm{Cu}_{51} \mathrm{Zr}_{14}$ and $\mathrm{Cu}_{2} \mathrm{ZrTi}$ nanocrystals embedded in the matrix [41]. The difference in the microstructure of the as-cast BMG rod and melt-spun amorphous $\mathrm{Cu}$ Zr-Ti ribbon and the corresponding HPT induced devitrification products are presented by schematic free energy curves in Figure 3. Presumably, as some crystalline embryos already exist in the present as-cast BMG and are absent in the as-spun ribbon of the same composition (see the bottom images in Figure 3), the activation barrier for crystallization (indicated as $\Delta \mathrm{G}^{\star}$ ) is significantly reduced for the BMG rod with respect to the as-spun ribbon, due to the slight enthalpy increase $\left(\Delta \mathrm{H}_{B M G}>\Delta \mathrm{H}_{\text {ribbon }}\right)$. Therefore we can conclude that the presence of the embryos in the asprocessed state can promote the devitrification [50], which is already manifested in the formation of crystalline products during the initial plastic deformation of the compres-

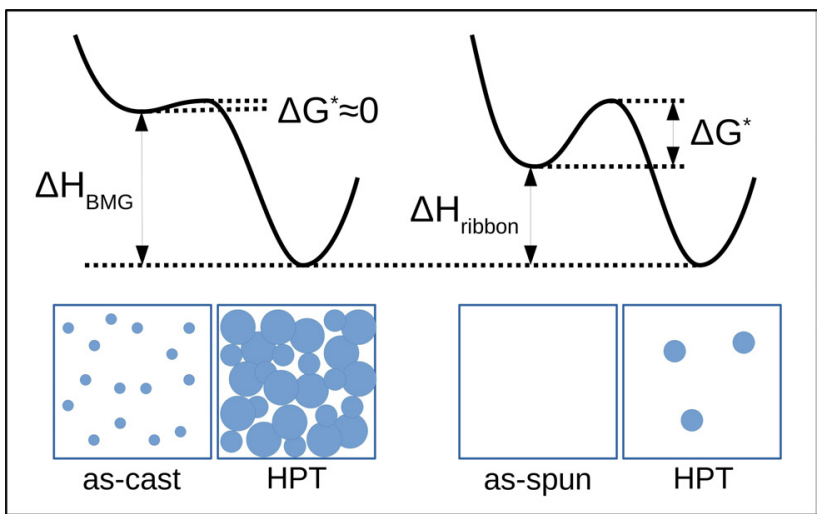

Figure 3: Schematic free energy curves of the as-cast $\mathrm{Cu}_{60} \mathrm{Zr}_{20} \mathrm{Ti}_{20}$ $B M G$ and the corresponding amorphous ribbon. $\triangle \mathrm{H}_{B M G}$ and $\Delta \mathrm{H}_{\text {ribbon }}$ denotes the enthalpy release during continuous calorimetric measurement. $\Delta \mathrm{G}^{*}$ is the activation barrier for nucleation. Bottom images indicate that the as-cast BMG glass contains crystalline embryos, contrary to the as-spun ribbon, which is fully amorphous. The microstructure obtained after HPT deformation also reveals significant differences, the strained BMG is almost fully crystalline, while the deformed ribbon still contains a significant amount of the amorphous phase.

sion of the HPT ( $\mathrm{N}=0)$, as was confirmed by the corresponding XRD pattern in Figure 2. As one can notice, there is only a slight change in the patterns when the shear straining is introduced, the peaks become more broad and overlap each other as the number of rotations $(\mathrm{N})$ increases. At the same time the corresponding DSC signals also undergo significant changes (see Figure 2a). The glass transition practically vanishes for all deformed samples while the total enthalpy release $\left(\Delta \mathrm{H}_{B M G}\right)$ drops down to $\sim 7-10$ percent of the initial value, confirming that HPT results in an amorphous nanocomposite structure with only small amorphous content.

Detailed analysis of the XRD peak positons revealed the $a$ parameter of both hexagonal phases is, on average, about 0.4-0.5 percent lower than the literature value (Figures $4 \mathrm{a}$ and $\mathrm{b}$ ), while the $c$ parameter of the $\mathrm{Cu}_{2} \mathrm{ZrTi}$ phase slightly exceeds it at the initial $(\mathrm{N}=0)$ and final $(\mathrm{N}=5)$ stages of the HPT deformation. On contrary, the $c$ parameter of the $\mathrm{Cu}_{51} \mathrm{Zr}_{14}$ phase is systematically and significantly smaller, reaching a minimum of 96.7 percent of the literature value at the early period $(\mathrm{N}=0.2)$ of deformation, while it increases up to $\sim 100$ percent at the largest deformation $(\mathrm{N}=5)$. From the lattice parameters plotted in Figure 4, one can calculate the unit cell volume of the two hexagonal phases. Accordingly, this volume shows an increasing trend with the rotation number from a value 4 percent below the literature data to minus 1 percent for the $\mathrm{Cu}_{51} \mathrm{Zr}_{14}$ phase, while it is about $1 \%$ less for the $\mathrm{Cu}_{2} \mathrm{ZrTi}$ phase, independent of the applied shear strain. 


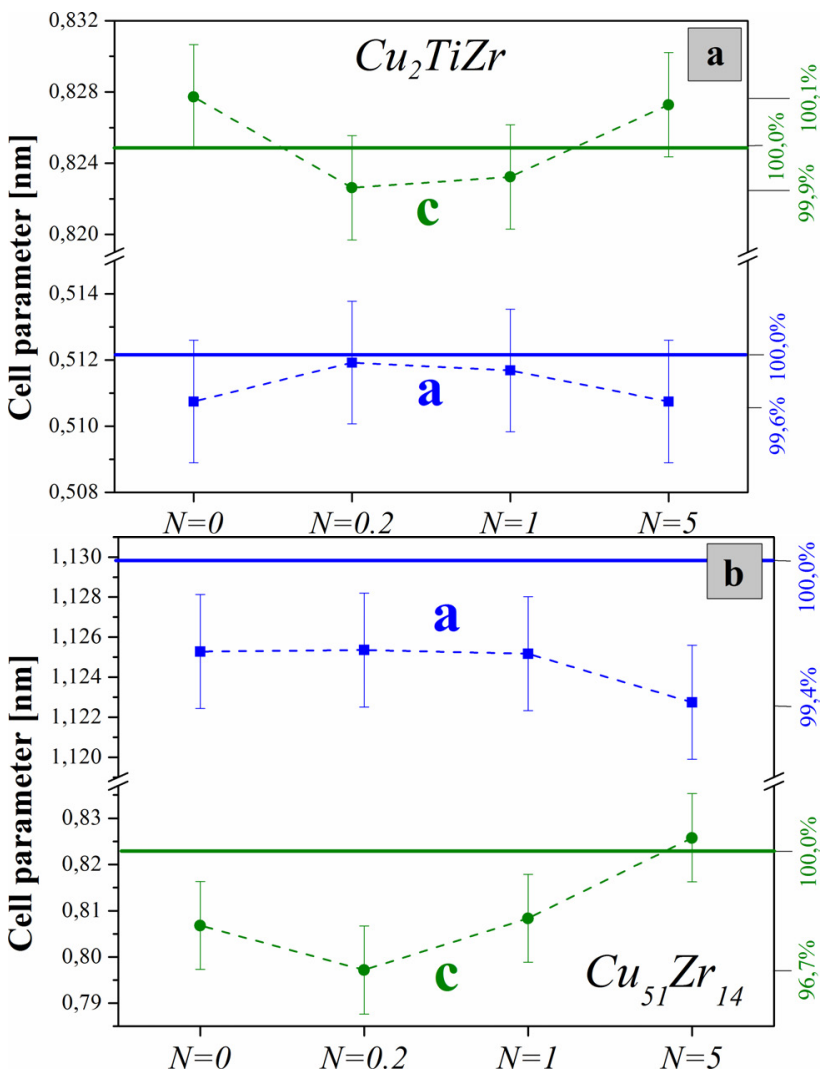

Figure 4: Calculated hexagonal cell parameters of the (a) $\mathrm{Cu}_{2} \mathrm{ZrTi}$ and (b) $\mathrm{Cu}_{51} \mathrm{Zr}_{14}$ phases in the as-cast and deformed states. For comparison, the equilibrium cell parameters (horizontal lines) and the relative cell parameter variation are also indicated.

The difference between the calculated and the literature unit cell parameters may be explained by the difference in the composition of the as-cast $\mathrm{Cu}_{60} \mathrm{Zr}_{20} \mathrm{Ti}_{20}$ material and the mixture of the $\mathrm{Cu}_{51} \mathrm{Zr}_{14}$ and $\mathrm{Cu}_{2} \mathrm{ZrTi}$ phases with exact stoichiometric composition. In details, the mixture of the two phases lacks about 10 at.\% $\mathrm{Zr}$ and substitution of $\mathrm{Zr}$ with the $\mathrm{Cu}$ or $\mathrm{Ti}$ atoms should result in distortions of the equilibrium crystalline structures due to the large size difference $\left(\mathrm{r}_{C u}=1.35 \AA \mathrm{r}_{T i}=1.4 \AA\right.$, $\mathrm{r}_{Z r}=1.55 \AA$ ) of the components. On average, the radius of a $\mathrm{Zr}$ atom is $11-15 \%$ higher than that of the two other components, therefore substitution of $10 \% \mathrm{Zr}$ atom is equivalent to $3-4.5 \%$ volume change if the metallic crystalline structure relaxes to fill the available volume optimally. Evidently, this volume change is in good agreement with that of the $\mathrm{Cu}_{51} \mathrm{Zr}_{14}$ phase (about $4 \%$ ), but for the $\mathrm{Cu}_{2}$ TiZr lattice the measured volume change is smaller (it is about $1 \%$ ), which indicates some stability and less relaxation possibility in the structure with the smaller unit cell.

A typical example of the CMWP fit together with the measured signal and difference plot is shown in Figure 5.

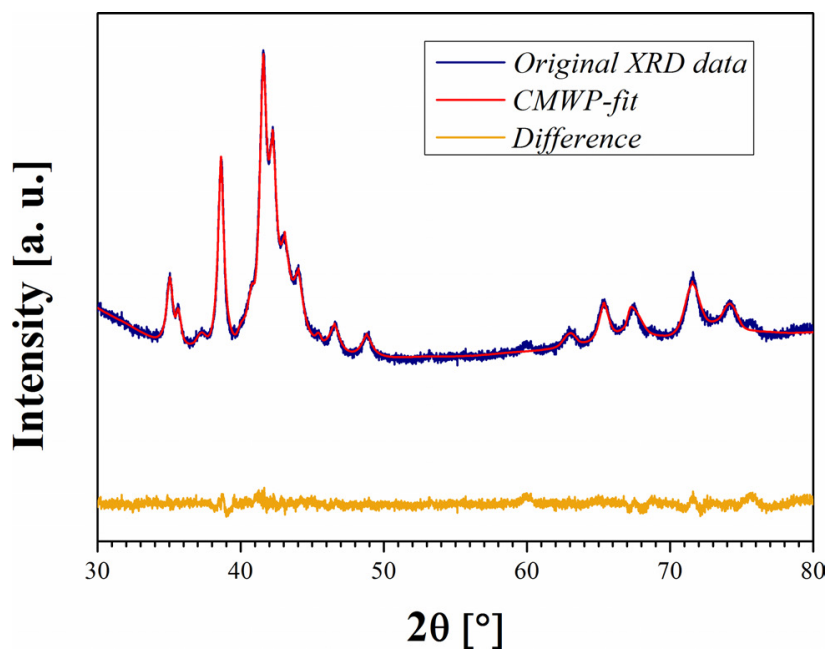

Figure 5: XRD pattern of the sample in the $\mathrm{N}=0$ state with the CMWP fit. The difference between the measured data and the CMWP fit is also indicated.
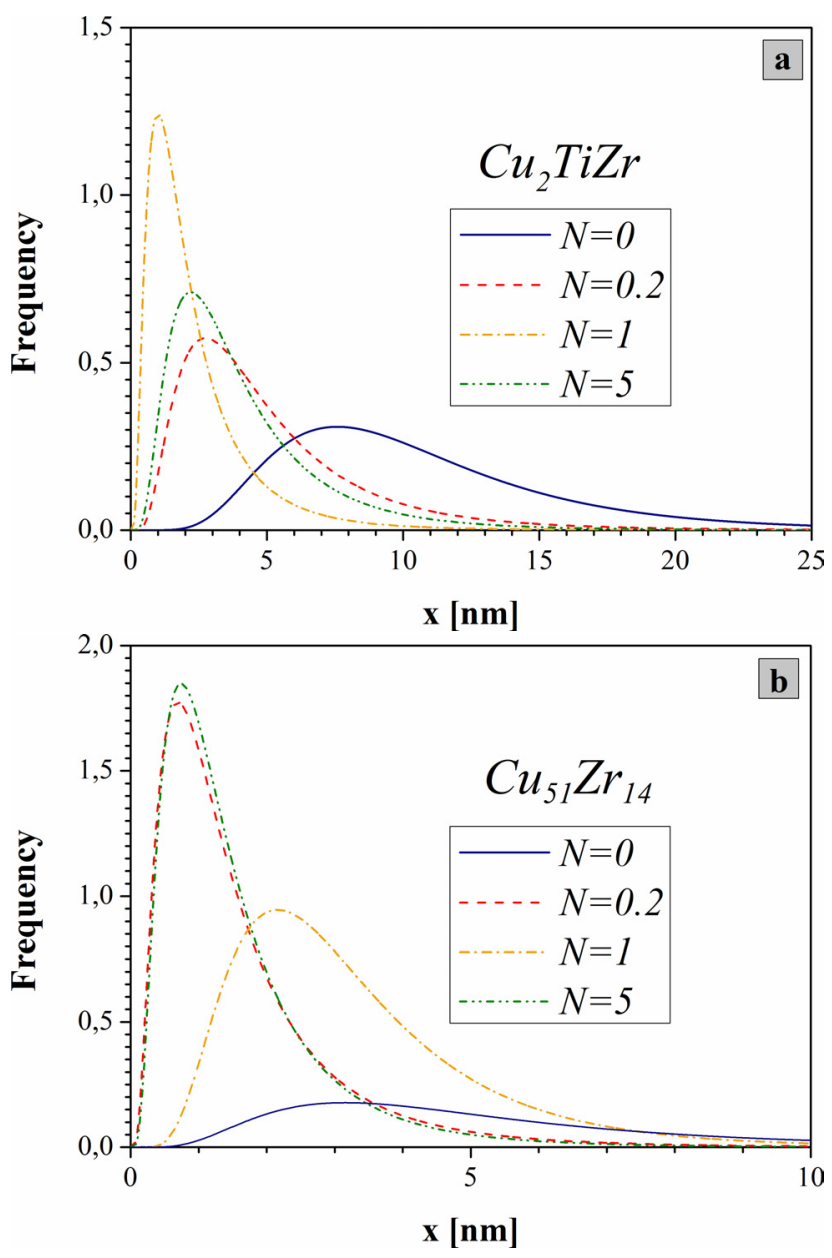

Figure 6: Crystal size distributions determined by CMWP fitting of the (a) $\mathrm{Cu}_{2} \mathrm{ZrTi}$ and (b) $\mathrm{Cu}_{51} \mathrm{Zr}_{14}$ phases for the different deformed states. 

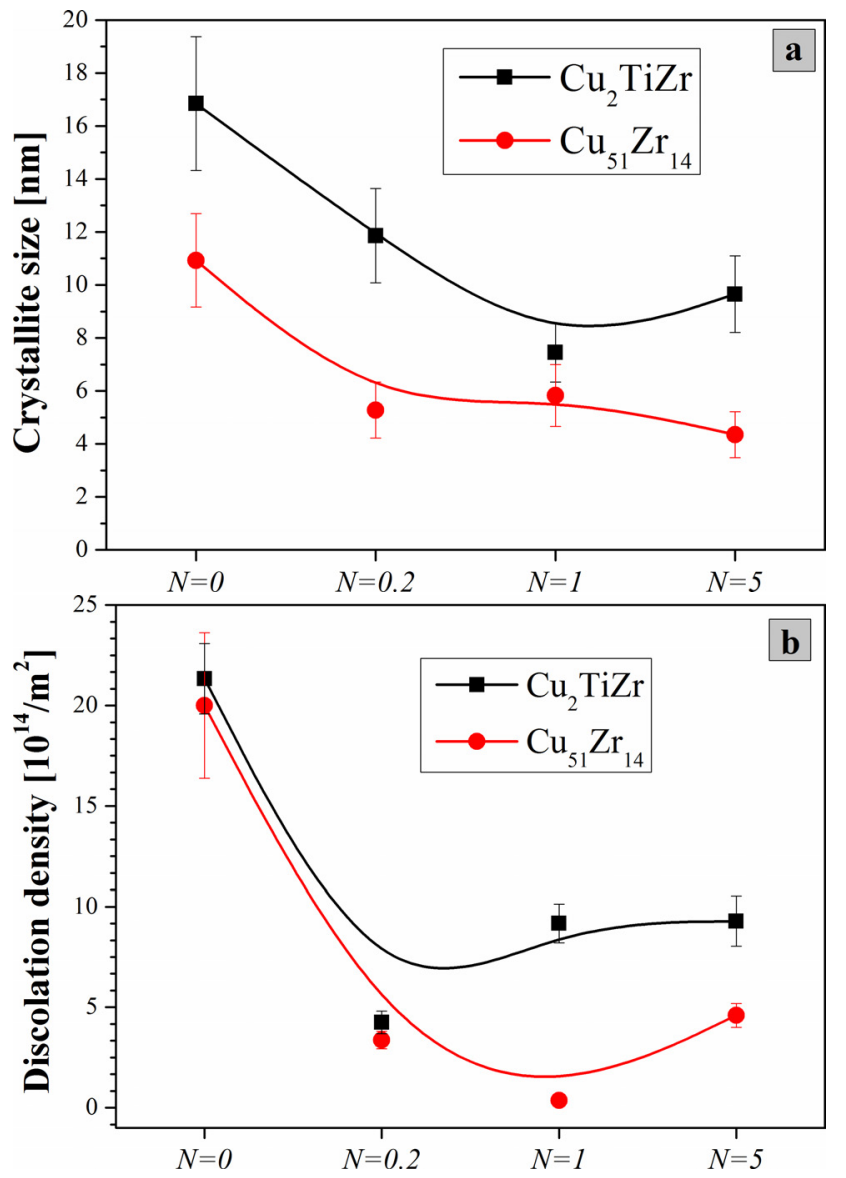

Figure 7: (a) Crystalline size $\langle\mathrm{D}\rangle$ and (b) dislocation density $(\rho)$ of the $\mathrm{Cu}_{2} \mathrm{ZrTi}$ and $\mathrm{Cu}_{51} \mathrm{Zr}_{14}$ phases determined by the CMWP fit for the different deformed states.

An almost perfect overlap between the whole fitted and measured patterns is evident, confirming that the numerical iteration during the CMWP analysis converged satisfactorily. From the available data of $\mathrm{m}$ and $\sigma$, the normalized crystallite size-distribution functions (see Eq. 2) can be constructed for both hexagonal phases. As seen in Figure $6 \mathrm{a}$, the histograms corresponding to $\mathrm{Cu}_{2} \mathrm{ZrTi}$ obeys a significant narrowing with increasing torsional straining accompanied with a shift of the median to lower values indicating a homogenization on nanoscale and a simultaneous size reduction, even though a slight broadening of the histogram occurs at the final stage of the deformation $(\mathrm{N}=5)$. At the same time an almost gradual homogenization and crystallite size reduction can be visualized in Figure $6 \mathrm{~b}$ for the $\mathrm{Cu}_{51} \mathrm{Zr}_{14}$ phase. The corresponding calculated $\langle\mathrm{D}\rangle$ values are plotted for both hexagonal phases in Figure $7 \mathrm{a}$. As seen, there is an overall gradual decreasing tendency with increasing strain, reaching a final value of $\langle D\rangle=10 \mathrm{~nm}$ and $\langle\mathrm{D}\rangle=4 \mathrm{~nm}$ for the $\mathrm{Cu}_{2} \mathrm{ZrTi}$ and $\mathrm{Cu}_{51} \mathrm{Zr}_{14}$ phases, respectively. The average dislocation density values also obeys a decreasing tendency with the torsion number, indicating that part of the dislocations generated during the initial compression are annealed out during the subsequent shearing (Figure $7 \mathrm{~b}$ ). It is noted that the calculated average dislocation distance $\left(\mathrm{L}_{C}=\rho^{-1 / 2}\right)$ considerably exceeds the obtained average crystallite size $\langle\mathrm{D}\rangle$ at each deformed states for both phases, which means that most of the grains can be considered as defect-free. Accordingly, only $\sim 10$ percent of the crystallites contains at least one dislocation for the $\mathrm{N}=5$ state.

Figure 8 shows BSE images of the surface of $\mathrm{N}=0$, $\mathrm{N}=0.2, \mathrm{~N}=1$ and $\mathrm{N}=5$ deformed samples. As seen in Figure $8 \mathrm{a}$, homogeneous sample surface with some cracks can be observed in $\mathrm{N}=0$ sample. The cracks possibly opened up after unloading from high pressure compression test and they disappear after severe shear deformation with $\mathrm{N}=0.2, \mathrm{~N}=1$ and $\mathrm{N}=5$ (cf. Figure $8 \mathrm{~b}-8 \mathrm{~d}$ ). Based on the sensitivity of the BSE SEM mode on concentration fluctuations, the homogeneity of the as-cast alloys was retained for the $\mathrm{N}=0$ sample below the submicrometer range. However, in subsequent shear deformation in HPT (Figure $8 \mathrm{~b}-8 \mathrm{~d}$ ), inhomogeneous pattern emerged above the resolution of the BSE mode, and periodic whiter and darker regions can be observed indicating decomposition of lighter and heavier elements in the homogeneous matrix. This inhomogeneity is the strongest for the $\mathrm{N}=0.2$ sample indicating that beside the decomposition a homogenization process takes also place due to the severe shear deformation.

Hardness values determined from large number nanoindentation measurements for each sample are plotted as hardness distributions in Figure 9a-9e. The as-cast BMG exhibits a sharp HV distribution (Figure 9a) comparing to the deformed samples. This is typical for metallic glass samples, which show homogeneity and are relatively free from internal stresses in the as-cast state. However, a minor subpeak in the $\mathrm{HV}$ distribution at about $10 \mathrm{GPa}$ indicates some inhomogeneity in the microstructure of the as-cast BMG may relates to the presence of impurities or accidental devitrified region. The average of the HV distribution for the compressed sample (Figure 9b) is in coincidence with the position of the subpeak in Figure 9a indicating that the whole sample $(\mathrm{N}=0)$ is devitrified after compression in good agreement with the XRD and calorimetric results (see Figures 1 and 2). Figure 9f shows the average of the hardness $(\overline{H V})$ for the as-cast and different deformed states. As seen, the $\overline{H V}$ value of as-cast sample reaches $11.64 \mathrm{GPa}$, while for the deformed samples the $\mathrm{HV}$ is first decreasing to $8.4 \mathrm{GPa}$ and has a minimum for $\mathrm{N}=0.2$ state and then it increases and reaches $10.4 \mathrm{GPa}$ for $\mathrm{N}=5$. This behavior is similar to the evolution of the micro scale decomposition observed in the SEM images (Figure 8). The 

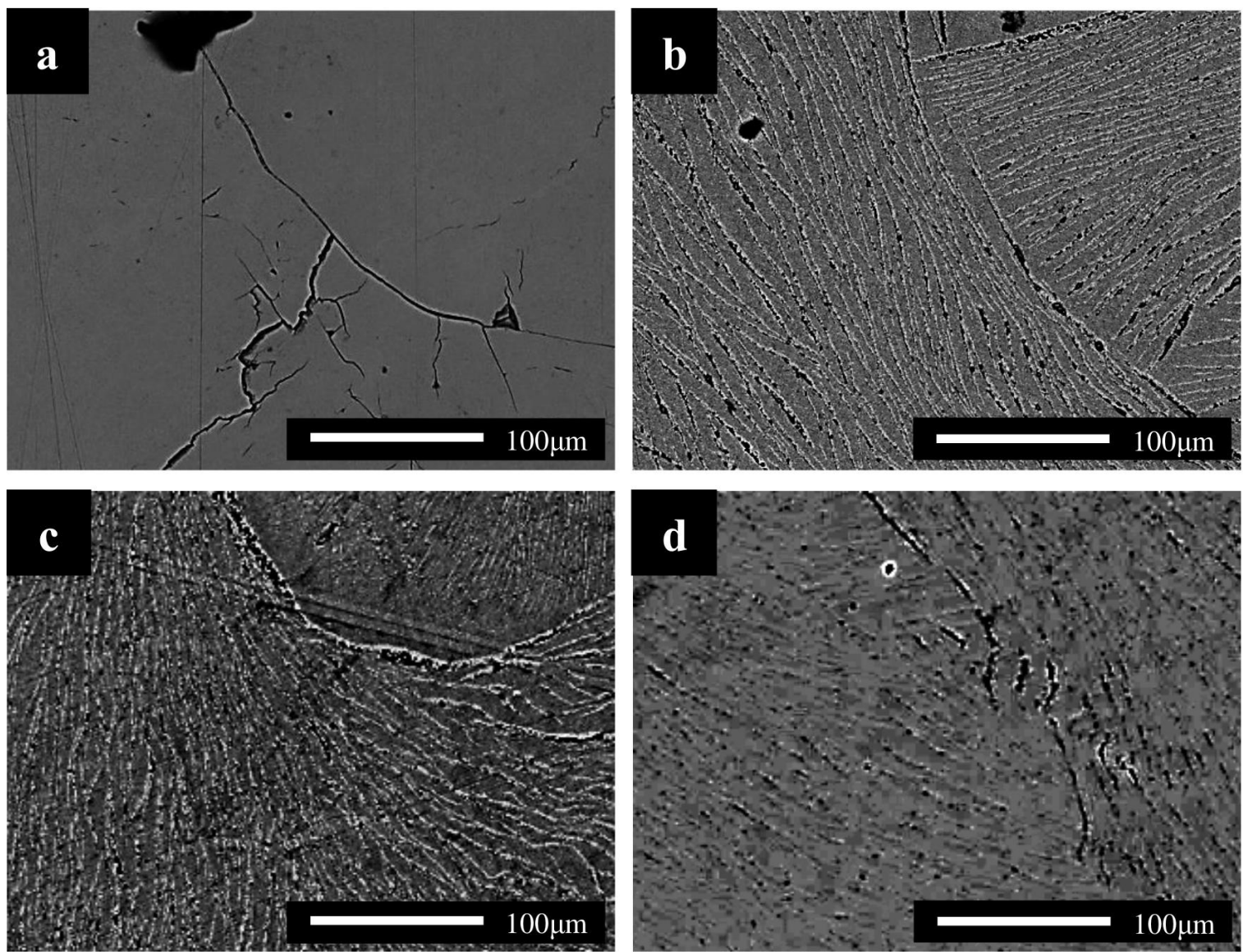

Figure 8: BSE SEM surface images of the (a) $\mathrm{N}=0$ compressed and (b) $\mathrm{N}=0.2$, (c) $\mathrm{N}=1$ and (d) $\mathrm{N}=5$ HPT samples.
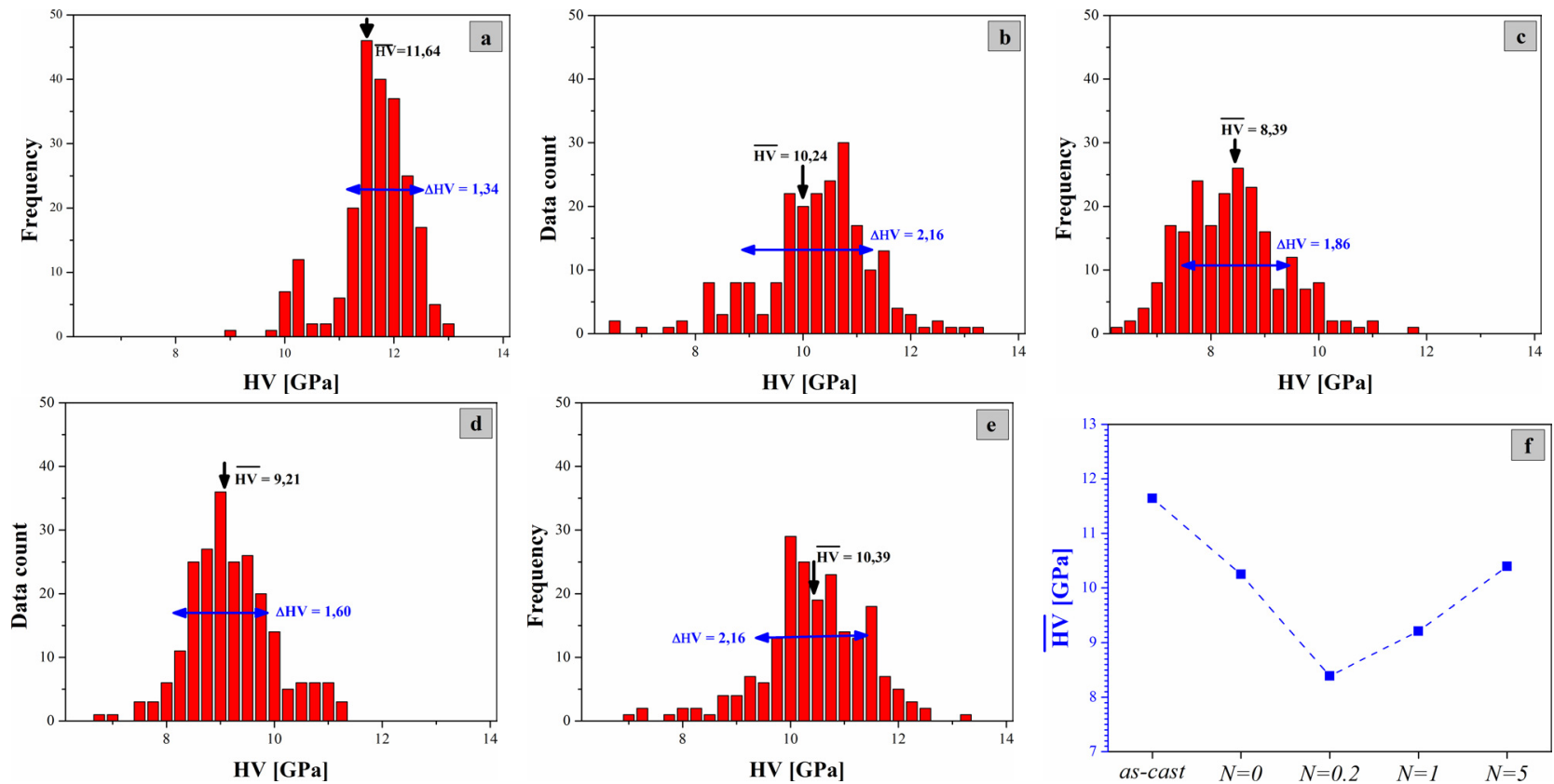

Figure 9: Distributions of the nanohardness values measured on the (a) as-cast, (b) $N=0$ compressed, (c) $N=0.2$, (d) $N=1$ and (e) $N=5$ HPT samples with the indicated averages and full widths of the distributions. (f) Variation of the average hardness for the different states. 
increasing tendency of $\overline{H V}$ with a slightly decreasing evolution of $\langle\mathrm{D}\rangle$ through torsion numbers from $\mathrm{N}=0.2$ to $\mathrm{N}=5$ can be explained by the Hall-Petch relationship [51].

\section{Conclusions}

Bulk metallic glass rod of $\mathrm{Cu}_{60} \mathrm{Zr}_{20} \mathrm{Ti}_{20}$ composition has been synthesized by copper mold casting technique. According to X-ray diffraction and linear heating calorimetric experiments, the as-cast glass is fully amorphous. Nevertheless the decaying heat signal recorded during isothermal annealing close to the glass transition temperature relates to a simple growth process of very tiny crystalline embryos. Slices of the as-cast glass has been subjected to severe plastic deformation by high-pressure torsion for $\mathrm{N}=0.2, \mathrm{~N}=1$ and $\mathrm{N}=5$ whole revolutions. The following findings have been established:

- Intensive crystallization of the bulk glass takes place during HPT-deformation, including the simultaneous formation of hexagonal $\mathrm{Cu}_{51} \mathrm{Zr}_{14}(\mathrm{p} 6 / \mathrm{m})$ and hexagonal $\mathrm{Cu}_{2} \mathrm{ZrTi}\left(\mathrm{p} 6_{3} / \mathrm{mmc}\right.$ ) phases.

- The CMWP X-ray line profile analysis revealed that there is an overall gradual decrease of the average crystallite size with increasing accumulated strain, reaching a final value of $\langle\mathrm{D}\rangle=10 \mathrm{~nm}$ and $\langle\mathrm{D}\rangle=4 \mathrm{~nm}$ for the $\mathrm{Cu}_{2} \mathrm{ZrTi}$ and $\mathrm{Cu}_{51} \mathrm{Zr}_{14}$ phases, respectively.

- The average dislocation density values also obeys a decreasing tendency with $\mathrm{N}$, indicating that part of the dislocations generated during the initial compression are annealed out during the subsequent shearing. Despite the large dislocation densities, most of the grains can be considered as defect-free.

- The average HV value of the as-cast sample is the highest among all the samples (11.64 $\mathrm{GPa}$ ), while $\mathrm{HV}$ reaches a minimum $(8.4 \mathrm{GPa})$ after $\mathrm{N}=0.2$ revolutions.

The experiments carried out in this research indicate that quenched-in nuclei can limit the stability of BMGs against external mechanical impacts. In the future, therefore other $\mathrm{Cu}$-Zr-Ti BMGs containing additional metallic elements, along with alternative glass synthesis routes, can be in the forefront of materials research in order to eliminate the nucleus formation during casting.

Acknowledgement: This work was completed in the ELTE Institutional Excellence Program (17833/2018/FEKUTSRAT) supported by the Hungarian Ministry of Human Capacities. G.R. is indebted for the Hungarian
Academy of Sciences for providing the Bolyai Research Grant.

\section{References}

[1] M. M. Trexler and N. N. Thadhani, Prog. Mater. Sci., 55 (2010) 759-839.

[2] A. L. Greer and E. Ma, MRS Bulletin, 32 (2007) 611-619.

[3] R. Yavari, J. J. Lewandowski, and J. Eckert, MRS Bulletin, 32 (2007) 635-638.

[4] Inoue, Acta Mater., 48 (2000) 279-306.

[5] M. Miller and P. Liaw, Bulk Metallic Glasses, Springer Publishing, New York, (2008).

[6] Y. Q. Cheng and E. Ma, Prog. Mater. Sci., 56 (2011) 379-473.

[7] D. B. Miracle, T. Egami, K. M. Floresa, and K. F. Kelton, MRS Bulletin, 32 (2007) 629-634.

[8] A. Schuh, T. C. Hufnagel, and U. Ramamurty, Acta Mater., 55 (2007) 4067-4109.

[9] A. H. Cai, Y. J. Feng, D. W. Ding, Y. Liu, H. Wu, Q. An, et al., J. Alloys Comp., 798 (2019) 273-279.

[10] Á. Révész, A. Concustell, L. K. Varga, S. Suriñach, and M.D. Baró, Mater. Sci. Eng. A, 375 (2004) 776-780.

[11] Y. Feng, A. H. Cai, D. W. Ding, Y. Liu, H. Wu, Q. An, et al., Mater Chem. Phys., 232 (2019) 452-459.

[12] K. Asami, C.-L. Qin, T. Zhang, and A. Inoue, Mater. Sci. Eng. A, 375-377 (2004) 235-239.

[13] A. Inoue and N. Nishiyama, MRS Bulletin, 32 (2007) 651-658.

[14] Inoue, W. Zhang, T. Zhang, and K. Kurosaka, J. Non-Cryst. Solids, 304 (2002) 200-209.

[15] Concustell, M. Zielinska, Á. Révész, L. K. Varga, S. Suriñach, and M. D. Baró, Interrmetallics, 12 (2004) 1063-1067.

[16] Q. Wang, J. Qiang, Y. Wang, J. Xia, and C. Dong, J. Non-Cryst. Solids, 353 (2007) 3425-3428.

[17] Y. Pan, Y. Zeng, L. Jing, L. Zhang and J. Pi, Mater. \& Design., 55 (2014) 773-777

[18] Xu, B. Lohwongwatan, G. Duan, W. L. Johnson, and C. Garland, Acta Mater., 52 (2004) 2621-2624.

[19] J. C. Lee, K. W. Park, K. H. Kim, E. Fleury, B. J. Lee, M. Wakeda et al., J. Mater. Res., 22 (2007) 3087-3097.

[20] S. Pauly, J. Bednarcik, U. Kühn, and J. Eckert, Scripta Mater,. 63 (2010) 336-338.

[21] S. Pauly, S. Gorantla, G. Wang, U. Kühn, and J. Eckert, Nat. Mater., 9 (2010) 473-477.

[22] Q. P. Cao, Y. H. Zhou, A. Horsewell, and J. Z. Jiang, J. Phys Cond. Matter., 15 (2003) 8703-8712.

[23] A. Concustell, Á. Révész, S. Surinach, L. K. Varga, G. Heunen, and M. D. Baró, J. Mater. Res., 19 (2004) 505-512.

[24] Aitkaliyeva, L. Shao, L. Price, J. Gigax, H. Kim, D. A. Lucca, et al., Nucl. Instrum. Meth. B, 448 (2019) 57-60.

[25] J. Z. Jiang, H. Kato, T. Ohsuna, J. Saida, A. Inoue, K. Saksl, et al., Appl. Phys. Lett., 83 (2003) 3299-3301.

[26] Q. P. Cao, J. F. Li, P. N. Zhang, A. Horsewell, J. Z. Jiang, and Y. H. Zhou, J. Phys. Cond. Matter 19 (2007) 246206.

[27] Y. Zhang, W. H. Wang, and A. L. Greer, Nature Materials, 5 (2006) 857-860.

[28] Y. H. Liu, G. Wang, R. J. Wang, D. Q. Zhao, M. X. Pan, and W. H. Wang, Science, 315 (2007) 1385-1388. 
[29] L. Q. Xing, Y. Li, K. T. Ramesh, J. Li, and C. Hufnagel, Phys. Rev. B, 64 (2001) 180201.

[30] X. K. Xi, D. Q. Zhao, M. X. Pan, W. H. Wang, Y. Wu, and J. J. Lewandowski, Phys. Rev. Lett., 94 (2005) 125510.

[31] R. J. Herbert, N. Boucharat, J. H. Perepezko, H. Rösner, and G. Wilde, J. Alloys Compd., 434-435 (2007) 252-254.

[32] J. Sort, D. C. Ile, A. P. Zhilyaev, A. Concustell, T. Czeppe, M. Stoica, et al., Scripta Mater., 50 (2004) 1221-1225.

[33] K. Edalati, I. Fujita, X. Sauvage, M. Arita, and Z. Horita, J. Alloys Compd., 779 (2019) 380-384.

[34] B. Straumal, O. A. Kogtenkova, R. Z. Valiev, P. Zieba, and B. Baretzky, Diffusion Found., 5 (2015) 95-108.

[35] Zs. Kovács, P. Henits, A. P. Zhilyaev, and Á. Révész, Scripta Mater., 54 (2006) 1733-1737.

[36] Á. Révész, E. Schaffler, and Zs. Kovács, Appl. Phys. Lett., 92 (2008) 011910.

[37] R. Z. Valiev, R. K. Ishlamgaliev, and I. V. Alexandrov, Prog. Mater. Sci. 45 (2000) 103-189.

[38] K. Edalati and Z. Horita, Mater. Sci. Eng. A, 652 (2016) 325-352.

[39] A. P. Zhilyaev and T. G. Langdon, Prog. Mater. Sci., 53 (2008) 893-979.
[40] R. Z. Valiev, A. P. Zhilyaev, and T. G. Langdon, Bulk Nanostructured Materials: Fundamentals and Applications, Wiley \& Sons, New Jersey, (2014).

[41] S. Hóbor, Á. Révész, P. J. Szabó, A. P. Zhilyaev, V. Kovács Kis, J. L. Lábár, et al., J. Appl. Phys., 104 (2008) 033525.

[42] S. Hóbor, Zs. Kovács, and Á. Révész, J. All. Comp., 495 (2010) 352-355.

[43] S. Hóbor, Zs. Kovács, and Á. Révész, J. Appl. Phys., 106 (2009) 023531.

[44] S. Hóbor, Zs. Kovács, A. P. Zhilyaev, L. K. Varga, P. J. Szabó, and Á. Révész, J. Phys: Conf. Series, 240 (2010) 012153.

[45] S. Hóbor, Zs. Kovács, and Á. Révész, J. All. Comp., 509 (2011) 8641-8648.

[46] G. Ribárik, J. Gubicza, and T. Ungár, Mat. Sci. Eng. A, 387-389 (2004) 343-347.

[47] T. Ungár, J .Gubicza, G. Ribárik, and A. Borbély, J. Appl. Cryst., 34 (2001) 298-310.

[48] W. C. Oliver and G. M. Pharr, J. Mater. Res., 7 (1992) 1564-1583.

[49] L. C. Chen and F. Spaepen, Nature, 336 (1988) 366-368.

[50] D.J. Browne, Z. Kovács, W. U. Mirihanage, Transactions of the Indian Institute of Metals, 62 (2009) 409-412.

[51] O. Hall, Proc. Phys. Soc. B, 64 (1951) 747-753. 